\title{
Are Novice Managers Ready for Business Interaction in A VUCA Environment?
}

Titova $0^{*}$

Department of psychology, Russia

Keywords: Tolerance to uncertainty; Relation to business interaction; Business interaction; Competence of business relations; Competition; Business partnership

\section{Introduction}

The study revealed that future managers with a high and low level of tolerance for

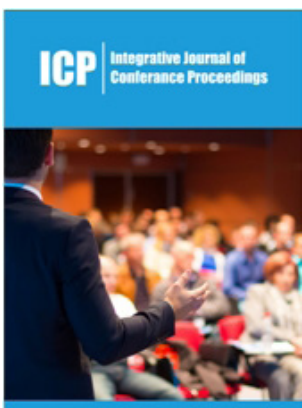

*Corresponding author: Titova 0 , Department of psychology, Krasnoyarsk State Pedagogical University Russia Submission: 齿 February 25, 2020

Published: 制April 06, 2020

Volume 2 - Issue 2

How to cite this article: Titova 0 . Are Novice Managers Ready for Business Interaction in A VUCA Environment?. Int J Conf Proc.2(2). ICP.000534.2020.

Copyright@ Titova 0, This article is distributed under the terms of the Creative Commons Attribution 4.0 International License, which permits unrestricted use and redistribution provided that the original author and source are credited. who are more prepared to work in the face of change are less oriented towards joint activities uncertainty, which determines the psychological readiness of a person to live in a VUCA environment, differ in their preferences for types of business interactions. Beginner managers in project teams. And, on the contrary, novice managers with more well-formed teamwork competencies have low tolerance for uncertainty and are thus less psychologically prepared for activities in the conditions of changes, in the VUCA environment.The need to ensure the production of competitive goods and services, including high-tech ones, is dictated by the demand for managers who could manage the enterprise in the conditions of constant uncertainty of the economic situation. The ability to work in project teams, effectively interact with the team, make responsible managerial and economic decisions-all this is only a small part of the real expectations of society and enterprises of the modern economy, regarding future managers studying in economic programs.

The professional activity of managers for which they should be prepared, to a large extent, involves activities in the face of uncertainty, due to the dynamics of the development of the socio-economic situation in society as a whole and in a particular enterprise in particular, and in addition-the influence of the so-called human factor on it-the variability of behavior and intentions of specific people with whom the manager interacts in the course of solving professional problems. At the same time, some of the young specialists are not ready to work effectively in the conditions of dynamic market relations, to change the profile of their activities when the development strategy of the enterprise changes, the technologies appearing on the market, sometimes they are not ready to show flexibility of thinking in resolving specific situations, to predict their possible consequences, especially when it comes to the need to carry out business interaction in joint activities.

The work of modern managers is associated with actions in the face of uncertainty and probabilistic scenarios. The source of uncertainty can be the state of the organization's external environment when forecasting and planning, which is influenced by the situation in the economy, scientific and technological achievements, sociocultural and political factors, international events, etc. When making decisions, it is precisely the conditions of uncertainty that are a characteristic condition for the manager's work, including due to the fact that information sources for the manager are often people with their inherent ability to distort, falsify this or that information. As noted in his dissertation research Leonov IN [1], that in connection with this important condition for joint activity in business relations is the manager's ability to make decisions in the face of uncertainty [1]. Thus, we believe that one of the key characteristics in the manager's personality structure is tolerance for uncertainty-a business quality that determines the manager's activities in a changing socio-economic situation, and ideas about interaction in business relations, about a partner, which in their entirety structure the picture of the world manager, determining his installation on decisionmaking, the choice of specific actions in professional activities.

Since novice managers after graduation are included in the system of socio-economic and managerial relations that already exists in society, in a particular organization, the results of 
a study of business partnership and competition in entrepreneurial and managerial activities are important for assessing their readiness for business interaction. Studying the attitude to business interaction, we relied on methodological approaches and the results of theoretical and empirical studies of business partnerships, competition in entrepreneurial and managerial activities, implemented jointly with Zhuravlev AL \& Poznyakov VP [2], Poznyakov VP \& Vavakina TS [3]. Among them are varieties of business interaction (competition for economic resources, competition-competition with personal achievements, technical and economic partnerships and personality-oriented partnerships); principles and norms of business partnership (equality, reciprocity, justice, responsibility), other indicators characterizing business interaction in joint activities.We took the definition of tolerance to uncertainty as a personal characteristic, expressed in a person's ability to endure uncertainty and anxiety about an unguaranteed and unpredictable future, in the willingness to accept uncertainty as a norm of life, in the willingness to creatively transform the surrounding reality into subjective certainty, proposed in the works of Lyubachevskaya EA [4].

The study involved bachelors of management $(\mathrm{N}=64)$ [5]. To collect empirical data, [6] and a business interaction study questionnaire [7] were used to determine uncertainty tolerance. Statistical data processing was carried out using the $\varphi$-criterion of the angular Fisher transform.An analysis of the data showed that half of the young managers participating in the study have a low level of tolerance for uncertainty, which indicates the tendency of respondents in this group to perceive unusual and complex situations as more threatening than giving new opportunities. Lack of information or its ambiguity makes them uncomfortable. Average values on the uncertainty tolerance scale are typical for $32.5 \%$ of respondents. A high level of tolerance to uncertainty is characteristic of $17.5 \%$ of respondents. Such managers can feel relatively comfortable even in a situation with a high level of variability, are able to act productively in an unfamiliar environment and, with a lack of information, take responsibility, are able to make decisions without long doubts and fear of failure, in an unusual situation they see the possibility of development and manifestation of their abilities and skills. Respondents were also asked to evaluate their preferences in relation to different types of competition and business partnerships, to assess the extent to which these or other resources they consider necessary for successful partnerships and competition, what qualities they tend to show in business relations, and what qualities another business person has interaction makes this interaction successful, psychologically comfortable. According to the results of an empirical study, the attitude to business interaction among students with a high and low level of tolerance to uncertainty is characterized as follows.

So, novice managers with a high level of tolerance for uncertainty are much more likely to show a high degree of preference for competition for economic resources (85\%), a high degree of preference for competition-competition for personal achievements in our sample was absolute- $100 \%$ of novice managers with a high tolerance for uncertainty. Preferences regarding partnerships among respondents with a high level of tolerance for uncertainty are characterized by the fact that they exhibit a medium degree of preference for technical and economic partnerships, the basis of which is the combination of various kinds of economic and material and technical resources. The average degree of preference for a personality-oriented partnership based on the significance of the business partner's qualities, emotional relations with him, similarity of values is characteristic of $85 \%$ of respondents with a high level of tolerance for uncertainty, and 15\% show a low degree of preference for this type of business interaction.Among novice managers with a low level of tolerance for uncertainty, one in four $(25 \%)$ rated their preference for competition for economic resources as corresponding to a low degree, and the rest, the main composition of this subgroup of respondents (75\%), prefer this type of business interaction at an average level. Competitioncompetition for personal achievements managers with a low level of tolerance for uncertainty also in most cases prefer an average level (65\%), every fifth (20\%) prefers this type of business interaction to a high degree, does not seek $7.5 \%$ respondents with low tolerance for uncertainty.

Regarding partnerships, the preferences of respondents with a low level of tolerance for uncertainty are characterized as follows: $60 \%$ of respondents prefer technical and economic partnerships at a high level, $35 \%$ at an average level, and $5 \%$ of managers with a low level of uncertainty tolerance at a low level. Subjective assessments of the preferences of managers with a low level of tolerance for uncertainty regarding personality-oriented partnerships were distributed in equal proportions between high and medium scoreshalf prefer this type of business partnership to a high degree, half to a medium degree.As factors/resources that ensure effective competition, managers with a high level of uncertainty tolerance choose such as the economic situation in society (42\%), the technologies used in the work (29\%) and stability and freedom of choice (29\%). Managers with a low level of tolerance believe that the reputation of your business (25\%), companionship (30\%) and trust within the team (25\%) are important to ensure effective competition.

Among the factors/resources that ensure effective partnerships, managers with a high level of tolerance for uncertainty highly value the role of the economic situation in society (43\%), reputation of activities (57\%), companionship (71\%), material and financial capabilities (57\%). Neutrally assessed factor is "trust within the team" (14\%). Managers with a low level of tolerance for uncertainty to ensure effective partnerships praised the role of partnerships (75\%), material and financial capabilities (80\%), and the economic situation in society (50\%). As obstacles to an effective partnership, the managers of this group described the stability and freedom of choice, the technical equipment used in the work of the technology. The significance of the technologies used in the work was assessed neutral by $30 \%$ of managers with a low level of tolerance for uncertainty and trust within the team (70\%).In business interactions with partners, managers with a low level of tolerance for uncertainty are guided by the principles of reciprocity (35\%), morality (30\%) and justice (25\%). Managers 
with a high level of tolerance for uncertainty in relations with partners focus on pragmatism (43\%) and equality (43\%).Also note that in relations with partners very often $(86 \%$ of managers with a high level of tolerance for uncertainty) use manipulations, often affect the partner (71\%) and from time to time follow the rule "trust, but verify" (71\%). Managers with a low level of tolerance for uncertainty very often (80\%) are confident in their partner and as many students completely trust their partners.

\section{Conclusion}

In conclusion, we summarize and outline the main results. First, we note that a significant proportion, namely half of the graduates, is characterized by low tolerance for uncertainty, which allows us to speak about the insufficient preparedness of future managers for professional activities in the changing conditions of modern society.It has been revealed that novice managers with a high tolerance for uncertainty are more likely to prefer competitive interaction than partnership, while competition-competition for personal achievements attracts them more than competition for economic resources. Managers with low tolerance for uncertainty prefer partnerships over competitive ones, and technical and economic partnerships are more than personality-oriented ones. Respondents with low tolerance to uncertainty indicate those based on relationships: personality, trust, companionship as personal factors of the effectiveness of competition. In partnerships, respondents with a high tolerance for uncertainty focus on pragmatism and equality; respondents with low tolerance for uncertainty-for reciprocity, morality and justice.

When comparing the results of an empirical study of the ideas of novice managers about business interaction, their preferences of one or another of its formats, orientation to principles in relations with business partners in joint activities and the requirements for modern managers, the following contradiction is revealed. Thus, managers with a high tolerance for uncertainty, respectively, more prepared for life in the face of changes, have less developed competencies associated with joint activities in the team, in project teams, since this category of managers demonstrates a preference for competitive relations, and much less focused on partnerships. And, on the contrary, managers who are focused on partnerships in joint activities, and thus predisposed to teamwork, have low tolerance for uncertainty and, therefore, less willingness to live in the face of change.The reported study was funded by RFBR, project number 19-013-00735.

\section{References}

1. Leonov IN (2015) The effect of tolerance on uncertainty on the professionally important qualities of a leader. Diss cand Psychol Science, p. 256.

2. Zhuravlev AL, Poznyakov VP, Titova OI (2013) Psychological relations of Russian entrepreneurs to competition and partnership: A gender aspect. Psychological studies of the problems of modern Russian society Ser. Proceedings of the Institute of Psychology Moscowpp, pp. 287-310.

3. Poznyakov VP, Vavakina TS (2016) The psychology of business partnership: Theory and empirical research. Monograph M : IP RAS, p. 320 .

4. Lyubachevskaya EA (2013) Tolerance to uncertainty as a personality phenomenon. Acmeology 3(47): 78-80.

5. Titova OI (2018) Tolerance to uncertainty as a factor in attitude to business interaction in the context of the development of general cultural competencies of university students. Siberian Psychological Journal 68: 131-142. DOI: 10.17223/17267080/68/8.

6. Soldatova LA (2008) Psychodiagnostics of personality tolerance: A practical guide. M Sense, p: 120.

7. Titova OI, Trukhina YuI (2014) Gender differences in the structure of the psychological attitude of entrepreneurs to business interaction. Bulletin of Tomsk State University 383: 196-201. 